\title{
BMJ Open Test characteristics of history, examination and investigations in the evaluation for septic arthritis in the child presenting with acute non- traumatic limp. A systematic review
}

Jacky Tu, ${ }^{1,2}$ Peter Gowdie, ${ }^{3,4}$ Julian Cassar, ${ }^{5}$ Simon Craig (1) 4,6,7

To cite: Tu J, Gowdie P,

Cassar J, et al. Test characteristics of history, examination and investigations in the evaluation for septic arthritis in the child presenting with acute non-traumatic limp. A systematic review. BMJ Open 2020;10:e038088. doi:10.1136/ bmjopen-2020-038088

- Prepublication history and additional material for this paper is available online. To view these files, please visit the journal online (http://dx.doi.org/10. 1136/bmjopen-2020-038088).

Received 28 February 2020 Revised 17 November 2020 Accepted 19 November 2020

Check for updates

(C) Author(s) (or their employer(s)) 2020. Re-use permitted under CC BY-NC. No commercial re-use. See rights and permissions. Published by BMJ.

For numbered affiliations see end of article.

Correspondence to

Dr Simon Craig;

Simon.Craig@monashhealth.org

\section{ABSTRACT}

Background Septic arthritis is an uncommon but potentially significant diagnosis to be considered when a child presents to the emergency department (ED) with non-traumatic limp. Our objective was to determine the diagnostic accuracy of clinical findings (history and examination) and investigation results (pathology tests and imaging) for the diagnosis of septic arthritis among children presenting with acute non-traumatic limp to the ED.

Methods Systematic review of the literature published between 1966 and June 2019 on MEDLINE and EMBASE databases. Studies were included if they evaluated children presenting with lower limb complaints and evaluated diagnostic performance of items from history, physical examination, laboratory testing or radiological examination. Data were independently extracted by two authors, and quality assessment was performed using the Quality Assessment Tool for Diagnostic Accuracy Studies 2 tool.

Results 18 studies were identified, and included 2672 children (560 with a final diagnosis of septic arthritis). There was substantial heterogeneity in inclusion criteria, study setting, definitions of specific variables and the gold standard used to confirm septic arthritis. Clinical and investigation findings were reported using varying definitions and cut-offs, and applied to differing study populations. Spectrum bias and poor-to-moderate study design quality limit their applicability to the ED setting. Single studies suggest that the presence of joint tenderness ( $\mathrm{n}=189$; positive likelihood ratio $11.4(95 \%$ Cl 5.9 to 22.0); negative likelihood ratio $0.2(95 \% \mathrm{Cl}$ 0.0 to 1.2)) and joint effusion on ultrasound ( $n=127$; positive likelihood ratio $8.4(95 \% \mathrm{Cl} 4.1$ to 17.1$)$; negative likelihood ratio 0.2 (95\% $\mathrm{Cl} 0.1$ to 0.3$)$ ) appear to be useful. Two promising clinical risk prediction tools were identified, however, their performance was notably lower when tested in external validation studies.

Discussion Differentiating children with septic arthritis from non-emergent disorders of non-traumatic limp remains a key diagnostic challenge for emergency physicians. There is a need for prospectively derived and validated ED-based clinical risk prediction tools.

\section{Strengths and limitations of this study}

- This review has synthesised and analysed in depth 18 studies relating to history, examination, imaging and pathology testing relevant to the diagnosis of septic arthritis in children.

- The review has performed an analysis of the quality of the studies, as well as the performance of various investigations and clinical findings.

- We searched the two major electronic medical databases from 1966, and limited our analysis to English-language articles, so there is a possibility that some studies were missed.

- There was substantial heterogeneity between studies, so we were unable to combine results.

- Changes to epidemiology (increasing prevalence of methicillin-resistant Staphylococcus aureus) and vaccine coverage (Streptococcus pneumoniae and Haemophilus influenzae) over recent years may have influenced how relevant older studies are to current clinical practice.

\section{INTRODUCTION}

Non-traumatic limp is a common paediatric presentation to the emergency department (ED). ${ }^{1}$ The differential diagnoses are broad, ranging from non-emergent disorders, such as transient synovitis and Legg-Calvé-Perthes disease, to urgent problems such as septic arthritis and slipped upper femoral epiphysis (SUFE). ${ }^{23}$ After excluding radiographic abnormalities such as Legg-Calvé-Perthes disease and SUFE in high-prevalence age groups, an important clinical question is how to differentiate septic arthritis from nonemergent disorders.

While the majority of children presenting with acute non-traumatic limp have transient synovitis (a benign, self-limiting cause that can be managed conservatively), a small proportion have septic arthritis, which can cause significant morbidity if diagnosis is 
delayed. ${ }^{4}$ Early diagnosis and treatment (ie, $\leq 4$ days from infection onset) is considered the most important prognostic factor in preventing acute complications such as sepsis and osteomyelitis, as well as long-term problems such as osteonecrosis, joint deformity and early onset osteoarthritis. ${ }^{5}$ Thus, the key issue for emergency physicians when evaluating the child presenting with nontraumatic limp is the accurate identification of children with septic arthritis from non-emergent disorders, while also minimising the use of painful and costly overinvestigation. ${ }^{67}$

This article aims to describe the published performance characteristics of clinical findings, laboratory testing, imaging and clinical prediction tools for the identification of septic arthritis among children presenting with acute non-traumatic limp in the ED setting.

\section{METHODS}

\section{Inclusion and exclusion criteria}

Studies that described paediatric patients presenting with monoarticular complaints (ie, limp, altered gait, nonweight bearing, limb pain or swelling) and contained original data on the utility of clinical history, physical examination, biochemical or radiographic findings in the diagnosis of septic arthritis were included. We only included studies which described a reference standard for diagnosis of septic arthritis. This could be achieved using any combination of abnormal synovial fluid macroscopic appearance, elevated white blood cell (WBC) count, synovial fluid and/or blood culture result.

Articles were excluded if they described patients who did not initially present with a monoarticular complaint; examined an adult study population or described a mixed study population (containing both adult and paediatric patients), where the reviewers were unable to extract data to determine sensitivities and specificities for the paediatric population; or if an article did not describe a reference standard for the diagnosis of septic arthritis.

As referral practices and the extent and timing of orthopaedic involvement in the diagnostic process vary between health systems, we did not exclude studies conducted outside the ED setting.

Apart from the information included in this publication and its supplementary material, no additional data are available.

\section{Patient and public involvement}

Patients and the public were not involved in the design or conduct of this research.

\section{Search strategy}

A structured search of the medical literature (Ovid MEDLINE and EMBASE) from January 1966 to June 2019 was conducted to identify articles that reported the diagnostic value of clinical, biochemical or radiographic findings for differentiating septic arthritis in the limping child from other aetiologies. The following Medical
Subject Headings were used in the search strategy: infectious arthritis combined with medical history taking, physical examination, routine diagnostic tests, diagnostic imaging, differential diagnosis or sensitivity and specificity AND cohort studies, observational study, retrospective studies or prospective studies. The full search strategy is available in online supplemental material 1. Two authors (JT, JC) independently screened the titles and abstracts of the search results. The full manuscript of each article was reviewed if at least one author considered it as potentially relevant.

\section{Quality of the evidence}

The overall quality of the included studies was evaluated by two authors (JT, JC) using the Quality Assessment Tool for Diagnostic Accuracy Studies 2 (QUADAS-2). ${ }^{8}$ Discrepant quality assessments were adjudicated by discussion with a third author (SC) and resolved by consensus. A kappa analysis using SPSS V.25.0 (SPSS, Chicago, Illinois, USA) was used to assess inter-rater agreement. ${ }^{9}$

The 'ideal' study population was defined as 'children presenting with a lower limb monoarticular complaint (limp, non-weight bearing status, altered gait, limb pain or swelling) to the ED, where 'septic arthritis' and 'nonseptic arthritis' were the two evaluated outcomes. Spectrum bias, however, may limit the validity of such studies when applied more broadly to an ED population. ${ }^{10}$ As such, if individual trials did not specifically recruit patients from the ED, the 'spectrum' portion of the QUADAS-2 tool was assessed as 'no'. Additionally, if the definition of the reference standard or blinding of index testers to the reference standard was not explicitly stated, these portions of the QUADAS-2 tool were assessed as 'no'. If the follow-up period of patients was not explicitly stated, 'Domain 4: Flow and Timing' was also assessed as 'no'.

\section{Data analysis}

A standardised data collection form was used by two authors $(\mathrm{JT}, \mathrm{JC})$ to independently extract data from the included studies. Data extracted included study characteristics (such as setting, sample size, inclusion and exclusion criteria) and study definitions for key diagnostic and outcome variables. The diagnostic test properties of key clinical, biochemical and radiographic findings were also extracted or calculated using the available information from the published paper.

Prior to our review, we standardised our definitions for the terms 'false negative', 'false positive', 'true positive' and 'true negative'. 'Disease' was defined as septic arthritis and 'no disease' was defined as an acute arthritis without bacterial aetiology or arthritis secondary to Borrelia burgodferi (ie, Lyme arthritis). The latter category included transient synovitis, Lyme arthritis and other non-emergent aetiologies of the limping child.

The diagnostic accuracy of the evaluated clinical and investigation parameters are presented as sensitivities and specificities and positive and negative likelihood ratios (LR), with 95\% CIs where appropriate. Discrepancies in 
assessment were discussed between three authors (JT, JC, SC) and resolved by consensus.

\section{Accuracy of signs and symptoms}

A number of clinical, biochemical and radiographic variables did not share the same definition across studies. For instance, a 'history of fever' had variable definitions across studies (ie, temperature $>37.0^{\circ} \mathrm{C}$ or $\geq 38.5^{\circ} \mathrm{C}$ ) and whether it was assessed prior, at time of $\mathrm{ED}$ presentation or during their inpatient stay. In each case, we defined the absence or presence of each variable on the basis of each individual study's specific definition.

\section{Statistical methods}

Sensitivity and specificity (with calculation of $95 \%$ CIs), forest plots and summary receiver operating curves were generated using Reviewer Manager (RevMan) (computer program, V.5.3, Copenhagen: The Nordic Cochrane Collaboration, 2014). LR were calculated using MedCalc for Windows (MedCalc Software, Ostend, Belgium) and SPSS V.25.0.

Our literature review commenced as a narrative literature review during a university honours year. We later attempted to register the systematic review on the PROSPERO database, but were unable to do so as the original literature searches and data extraction conducted as part of the honours year project rendered the review ineligible for prospective registration.

\section{RESULTS}

A total of 500 articles were identified, including 357 from the MEDLINE and 143 EMBASE medical literature databases, respectively (figure 1). Following exclusion of duplicate articles, 408 unique articles were screened for study eligibility. Of these, 282 articles were excluded on review of their titles and abstracts, and another 108

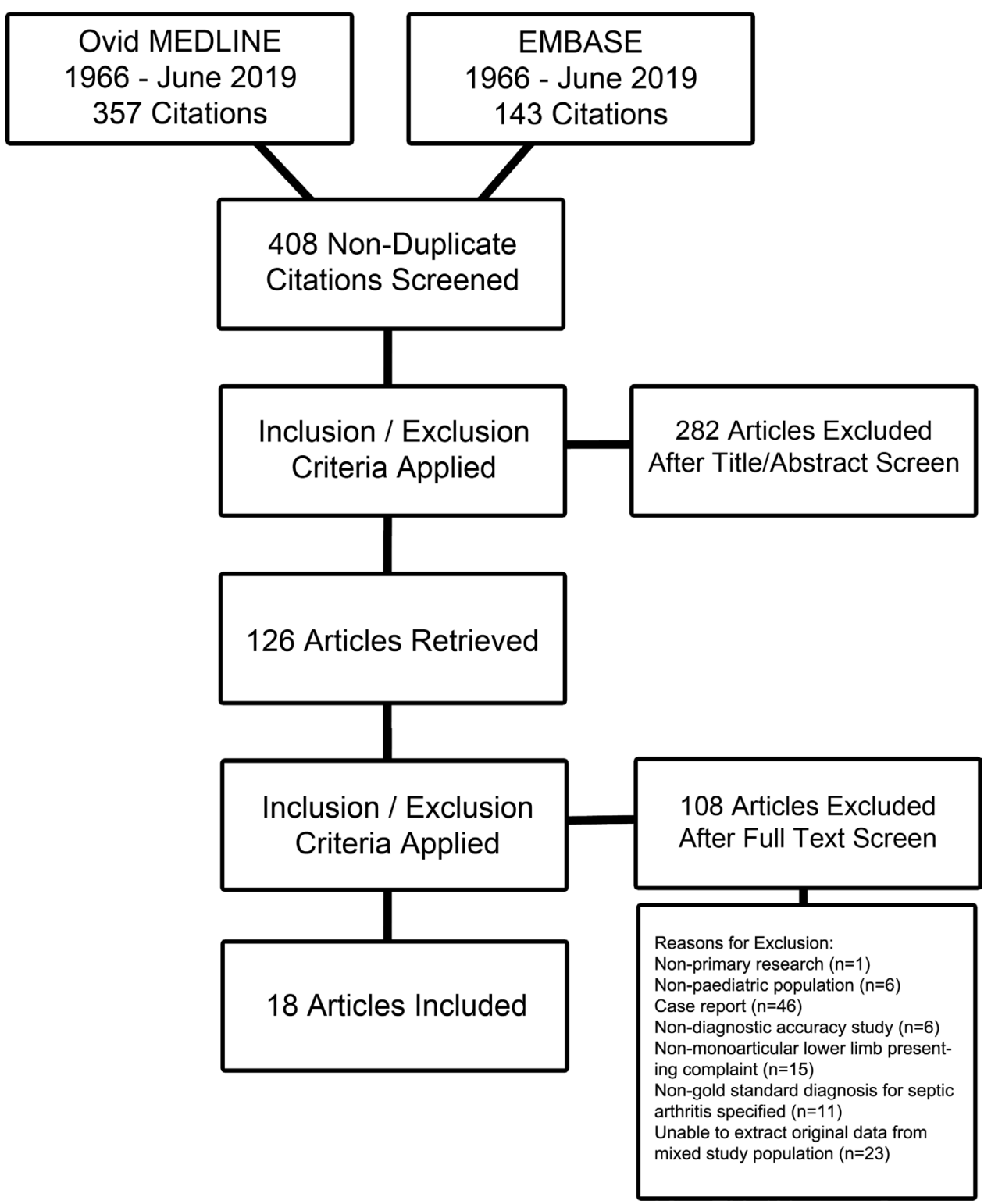

Figure 1 Study flow diagram. 
articles were excluded on review of their full manuscripts. Eighteen articles met all inclusion criteria.

Study characteristics and definitions for key diagnostic and outcome variables for the included 18 studies are summarised in table 1. Overall, 2672 patients presenting with lower limb complaints were included in our review, of whom 560 (21.0\%) were diagnosed with septic arthritis. These studies took place between 1979 and 2013 and their patient cohorts ranged from 18 to 474 patients. Of the 18 included studies, 12 were retrospective observational cohort studies, 4 were prospective observational cohort studies and 2 were case-control studies.

Only one study included children presenting to the ED with reduced range of motion (ROM) of a skeletal segment. ${ }^{11}$ Of the remaining studies of children presenting with lower limb complaints, nine studies examined children who also underwent joint aspiration, ${ }^{12-20}$ five examined children admitted as hospital inpatients for exclusion of septic arthritis, ${ }^{21-25}$ two examined children who underwent hip MRI for acute hip pain or limp 2627 and one examined children who had a hip effusion identified on ultrasonography. ${ }^{28}$ Only three studies explicitly included ED populations. ${ }^{11} 1617$

Two authors (JT, JC) independently performed a quality assessment of the 18 included studies using the QUADAS-2 assessment tool for diagnostic accuracy studies (see online supplemental material 2). The authors' QUADAS-2 assessment of quality had a kappa of range $0.82-1$.

The quality of the diagnostic accuracy studies for septic arthritis among children presenting with non-traumatic limp is highly variable. Eight studies included patients with a 'recent history of antibiotic use' without an explicit definition for this variable. Four studies also excluded patients on the basis of 'later development of rheumatological disease, Legg-Calvé-Perthes disease or associated proximal femoral osteomyelitis'.

The definition of 'septic arthritis' also varied between studies. Thirteen studies provided broad and detailed definitions for 'septic arthritis' on all key parameters including macroscopic appearance, synovial WBC count and presence/absence of a positive synovial fluid or blood culture result. Five provided limited definitions for septic arthritis: three studies defined it as 'gross pus on joint aspiration or drainage' only, but provided no comment on blood culture, synovial fluid or WBC count ${ }^{22}{ }^{2425}$; one defined it on the basis of a positive synovial fluid culture, but provided no comment on blood culture, synovial WBC count or macroscopic appearance ${ }^{23}$ and one defined it as a positive synovial fluid or blood culture, with associated 'numerous polymorphs seen on high-screen microscopy', but provided no explicit definition for 'numerous polymorphs'. ${ }^{21}$

No study reported the interval between the index test and the reference standard. In addition, no study explicitly described blinding assessors of the index test from the reference standard or vice versa. Six retrospective and two prospective cohort studies also included children in a control group who did not receive the same reference standard as those subsequently classified as 'septic arthritis' (ie, children classified as 'transient synovitis' was on the basis of 'clinical improvement from bed rest and analgesics alone without undergoing a joint aspiration', while children classified as 'septic arthritis' was on the basis of those who 'underwent a joint aspiration and diagnosed on the basis of synovial fluid or blood culture findings'). Of the six retrospective studies, none of these children was followed up to ensure they had not presented elsewhere and been treated for septic arthritis.

\section{Prevalence of septic arthritis}

Deanehan et $a l^{16}$ found that 19 (3\%) of the 673 children presenting to one of two urban paediatric centres in a Lyme disease-endemic area with acute knee monoarthritis between 1992 and 2012 had septic arthritis. Other estimates of septic arthritis in different study populations, including children who were admitted as a hospital inpatient for exclusion of septic arthritis and children who underwent joint aspiration are notably higher, with a prevalence of septic arthritis ranging from $5.2 \%$ to $75.6 \%$. No studies described ED prevalence of septic arthritis in a non-Lyme disease-endemic area.

\section{History and examination findings}

Eight studies provided sensitivity and specificity data enabling the calculation of positive and negative LR for the risk factors of septic arthritis among children presenting with non-traumatic limp (table 2). ${ }^{12-16}$ 21-23 None of male gender, history of tick bites, previous antibiotic use, history of chills, joint pain, Lyme season, a previous healthcare visit and recent illness had consistently useful LR to either rule in or rule out a diagnosis of septic arthritis.

Twelve studies examined the role of objective examination findings (table 3). ${ }^{11-16181921-24}$ The definition of fever varied from study to study, ranging from a temperature $\geq 37.0^{\circ} \mathrm{C}$ to $\geq 38.5^{\circ} \mathrm{C}$. The presence of any documented fever, irrespective of threshold, increased the risk of septic arthritis, although positive LR ranged from 2.0 to 25.2. The absence of fever had negative LR ranging from 0.2 to 0.8 .

The ability to weight-bear was assessed by eight studies. ${ }^{12-161819}$ This finding had variable performance in different studies, with positive LR ranging from 1.2 to 1.7 , and negative LR ranging from 0.1 to 0.9 .

Joint tenderness, limited ROM and joint warmth were less commonly assessed clinical variables. A single study suggested that joint tenderness may be a useful finding, with a positive LR of 11.4 (95\% CI 5.9 to 22.0), and a negative LR of 0.3 (95\% CI 0.2 to 0.5 ).

\section{Biochemical variables}

Six studies provided primary diagnostic data to evaluate the performance of an elevated WBC count in diagnosing septic arthritis among children presenting with lower limb complaints (table 4). ${ }^{12} 18$ 21-24 The definition of an 


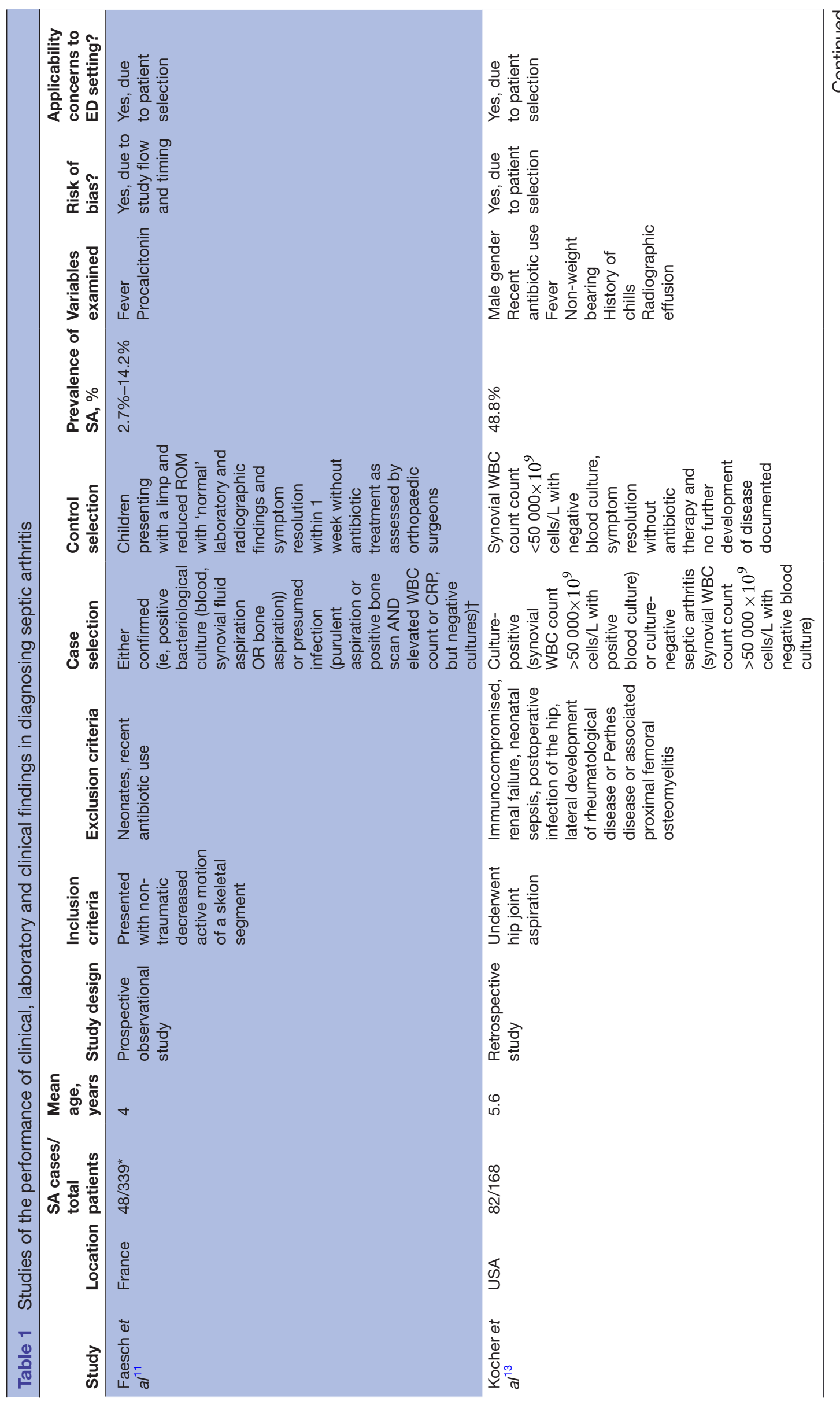




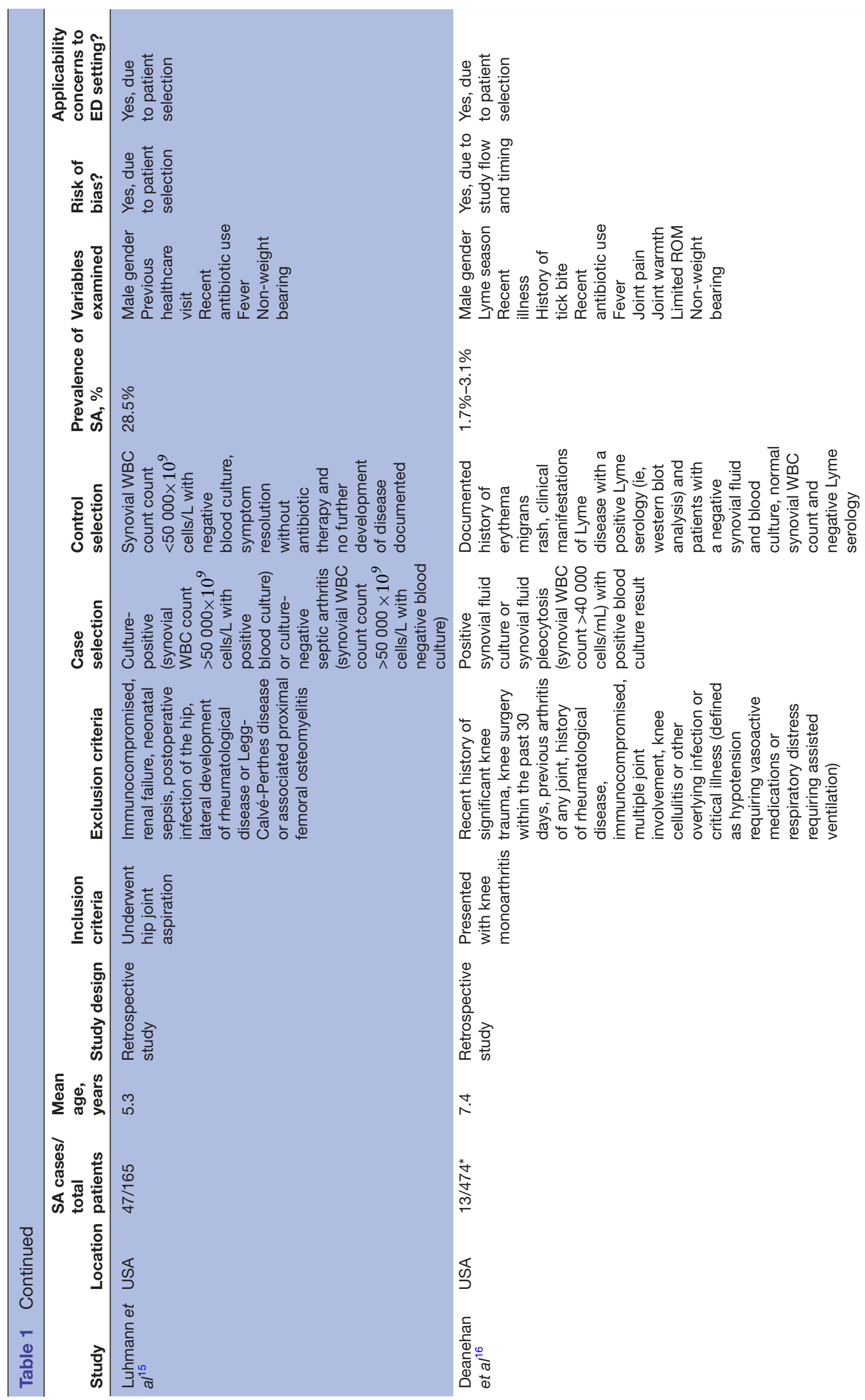




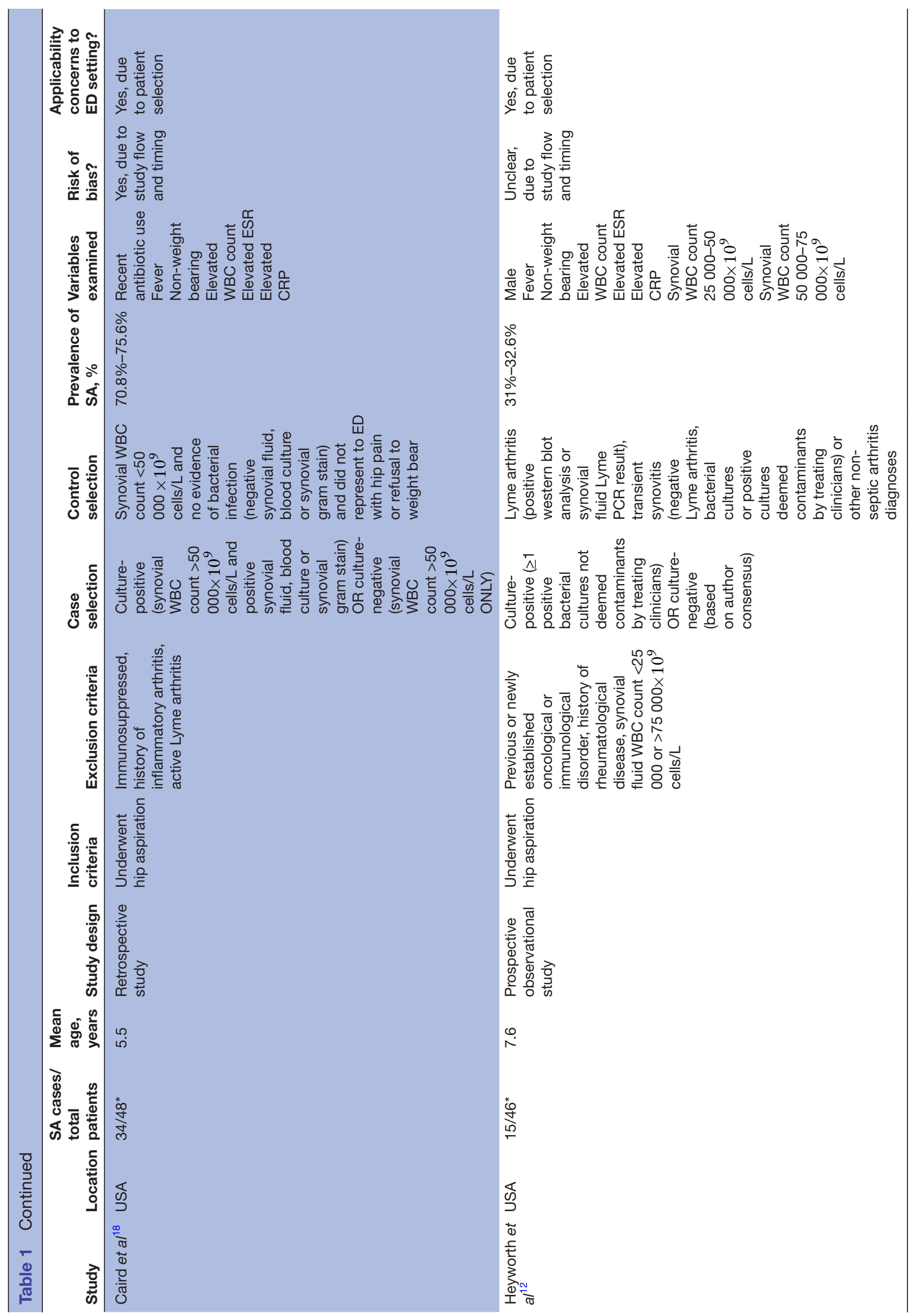




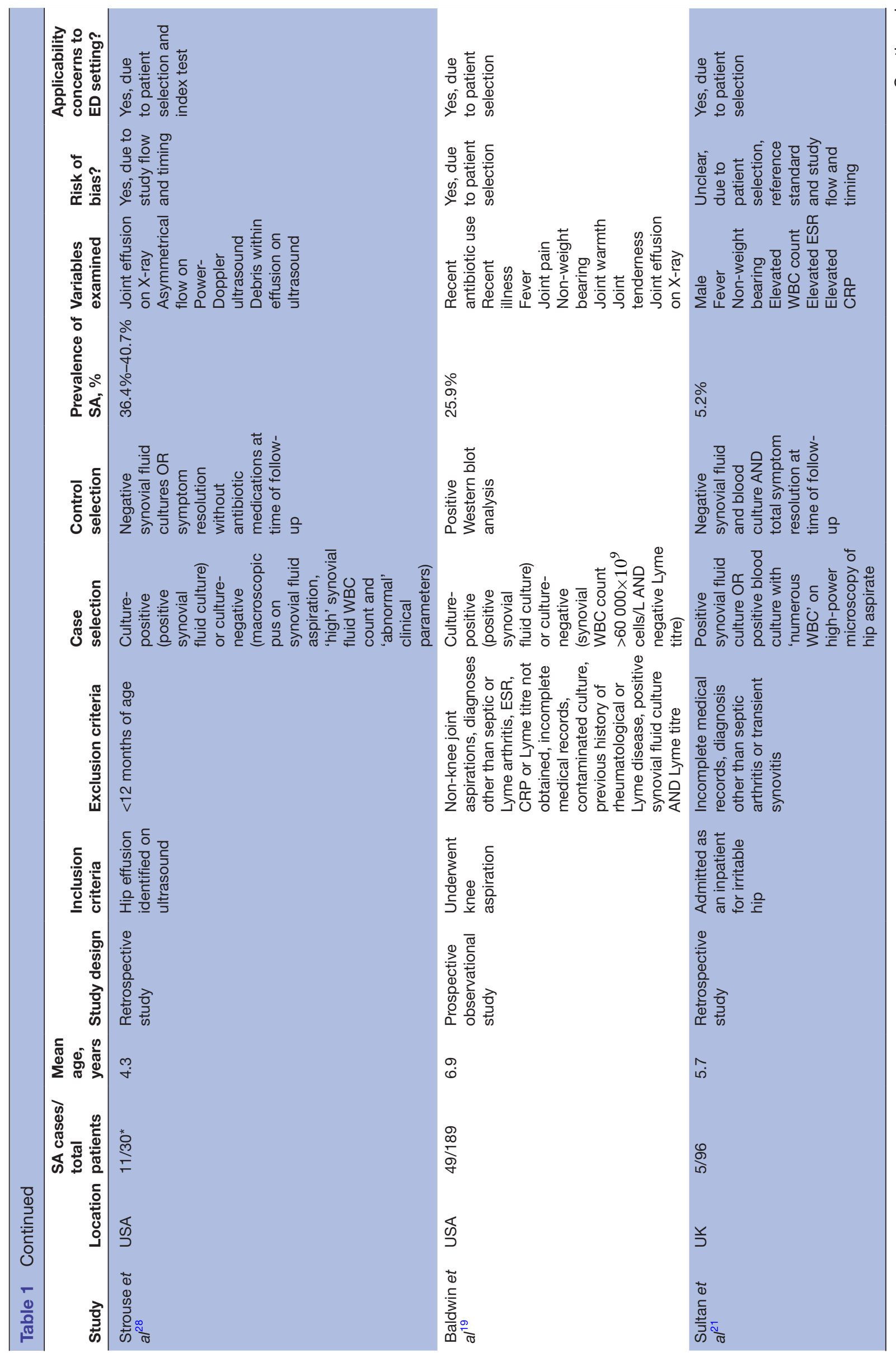




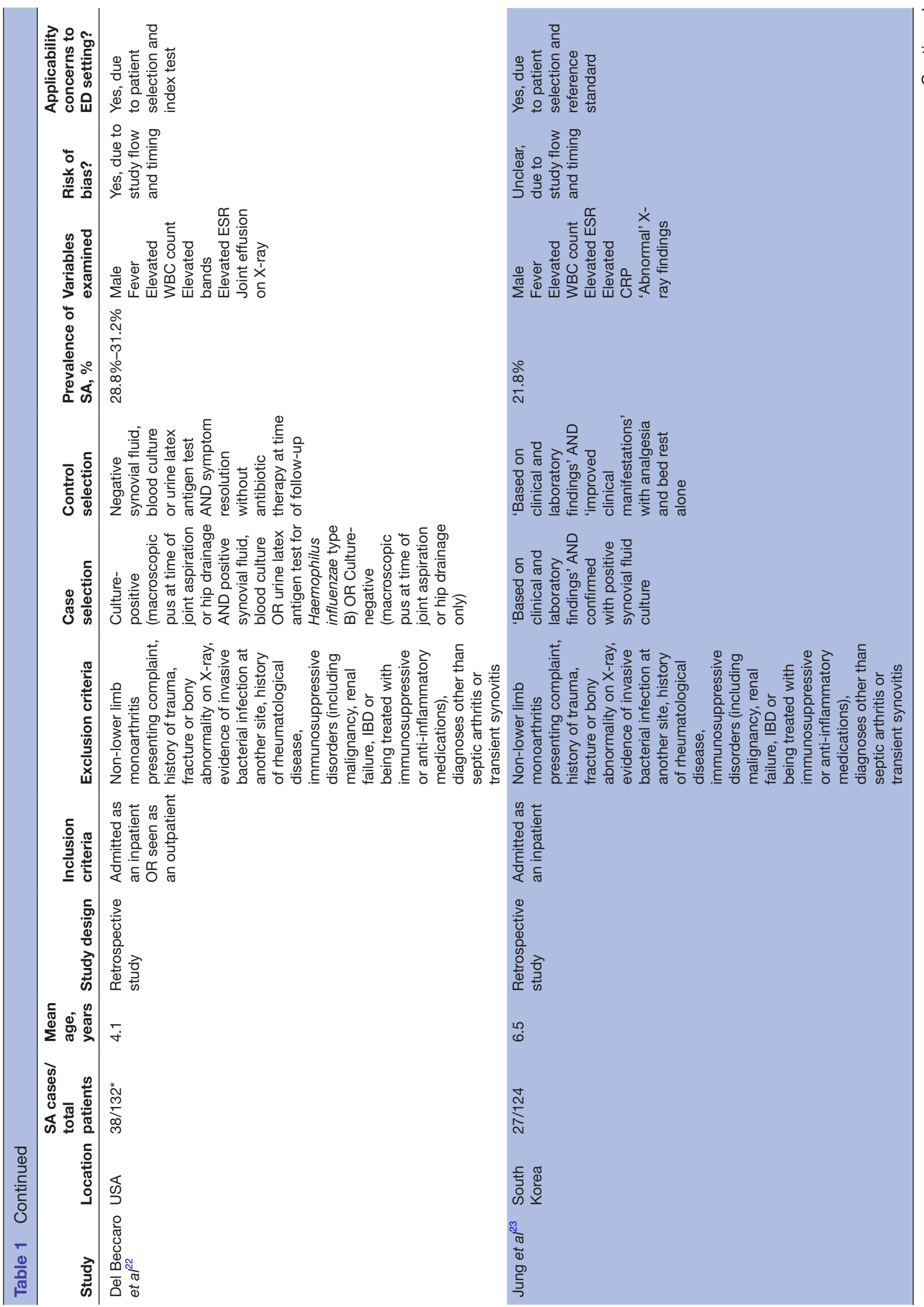




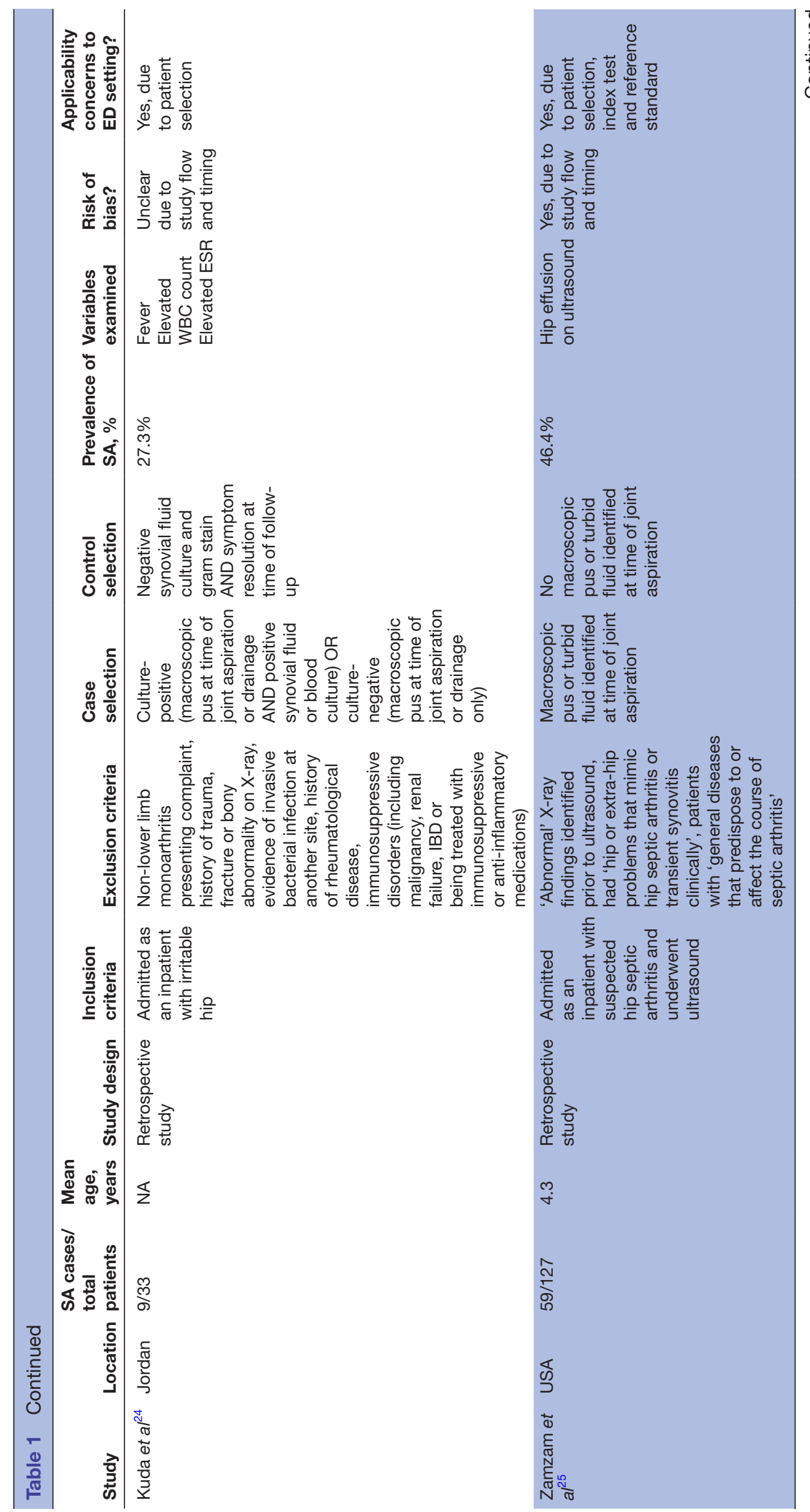




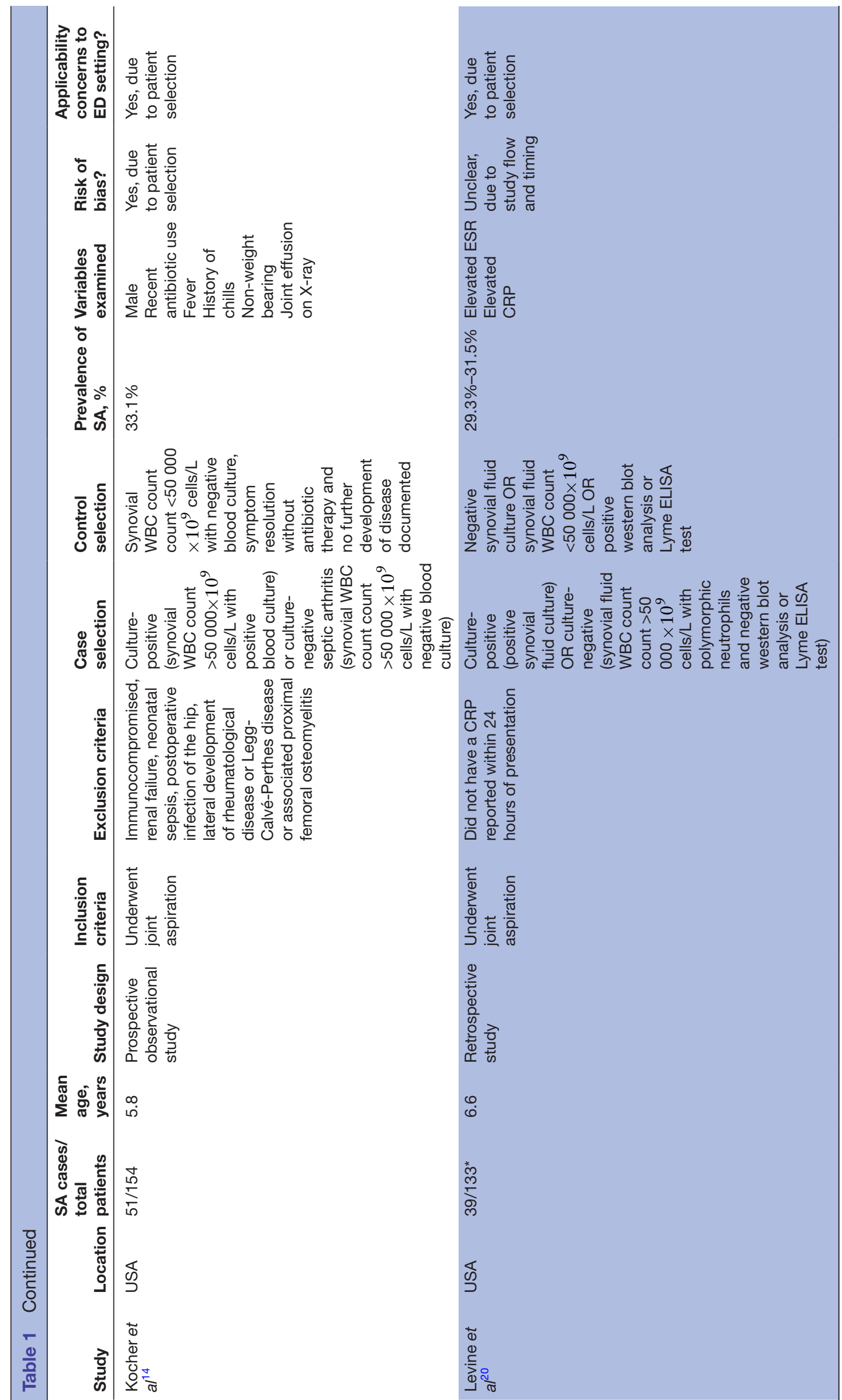




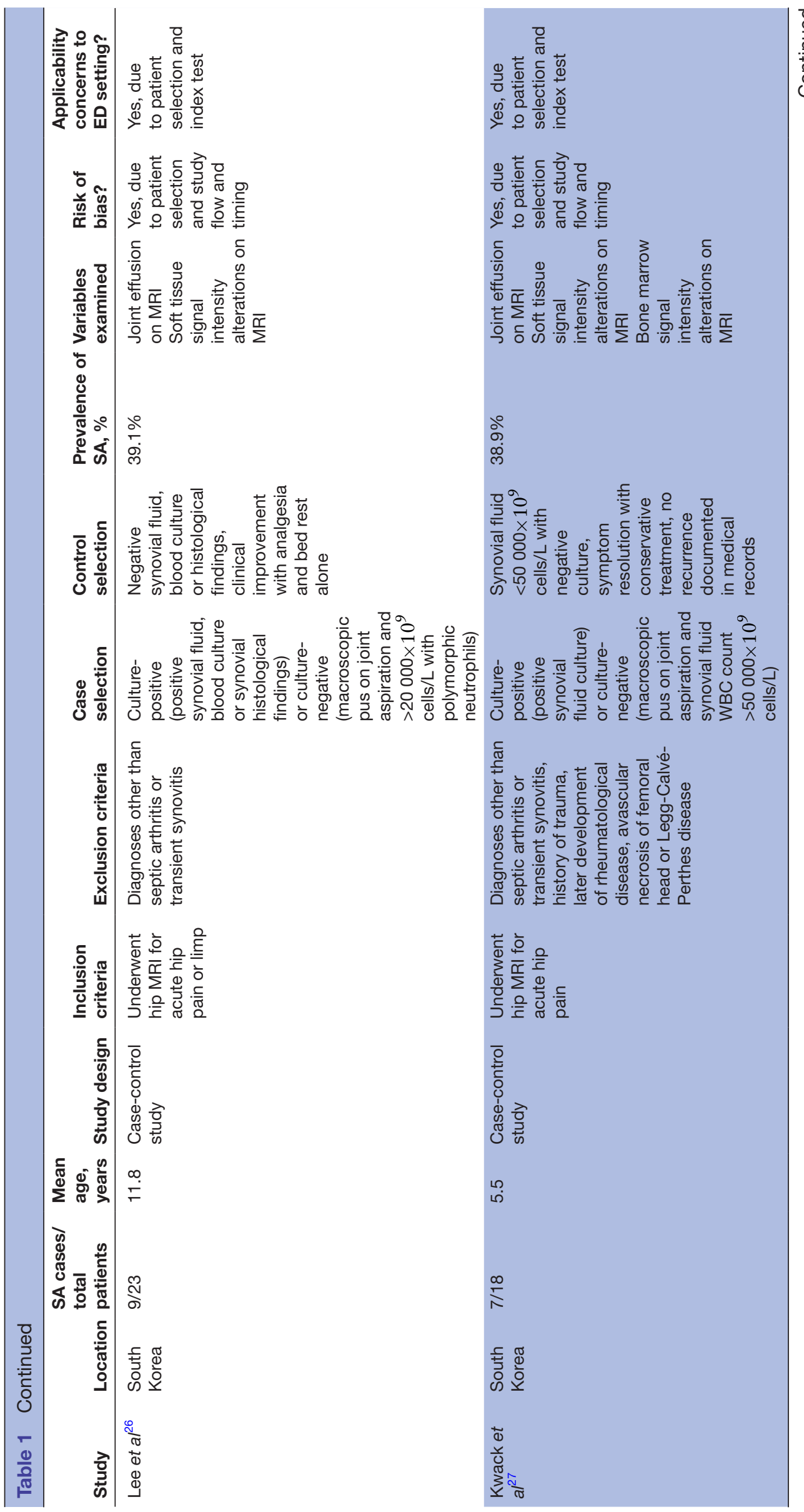



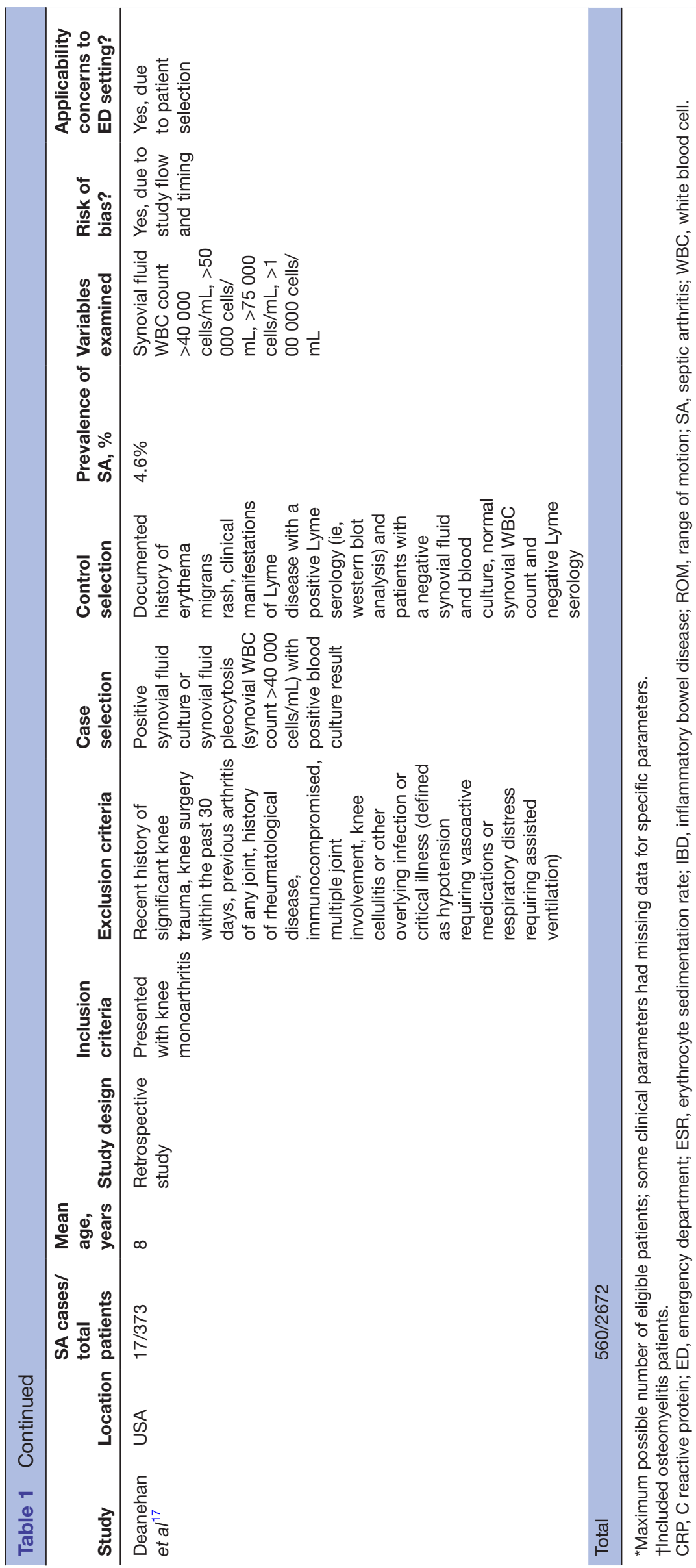

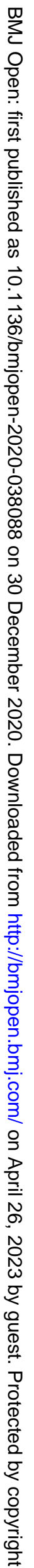


Table 2 Sensitivities, specificities and likelihood ratios for findings on history and examination

\begin{tabular}{|c|c|c|c|c|c|c|}
\hline \multirow[b]{2}{*}{ Risk factors } & \multirow[b]{2}{*}{ Study } & \multirow{2}{*}{$\begin{array}{l}\text { Prevalence } \\
\text { of SA, } \%\end{array}$} & \multirow{2}{*}{$\begin{array}{l}\text { Sensitivity } \\
\text { (95\% Cl) }\end{array}$} & \multirow{2}{*}{$\begin{array}{l}\text { Specificity } \\
\text { (95\% Cl) }\end{array}$} & \multicolumn{2}{|c|}{ Likelihood ratio $(95 \% \mathrm{Cl})$} \\
\hline & & & & & Positive (LR+) & Negative (LR-) \\
\hline \multicolumn{7}{|l|}{ History } \\
\hline \multirow{6}{*}{ Male } & Del Becarro et $\left.a\right|^{22}$ & 28.8 & $0.68(0.51$ to 0.82$)$ & 0.41 (0.31 to 0.52$)$ & 1.2 (0.9 to 1.5$)$ & 0.8 (0.5 to 1.3$)$ \\
\hline & Heyworth et $a l^{12}$ & 32.6 & $0.60(0.32$ to 0.84$)$ & $0.42(0.25$ to 0.61$)$ & 1.0 (0.6 to 1.7$)$ & 1.0 (0.5 to 2.0$)$ \\
\hline & Kocher et $a l^{13}$ & 48.8 & $0.50(0.39$ to 0.61$)$ & $0.34(0.24$ to 0.45$)$ & 0.8 (0.6 to 1.0$)$ & 1.5 (1.0 to 2.1$)$ \\
\hline & Kocher et al ${ }^{14}$ & 33.1 & $0.49(0.35$ to 0.63$)$ & 0.29 (0.21 to 0.39$)$ & 0.7 (0.5 to 0.9$)$ & 1.8 (1.2 to 2.6$)$ \\
\hline & Luhmann et $a l^{15}$ & 28.5 & $0.53(0.38$ to 0.68$)$ & $0.27(0.19$ to 0.36$)$ & 0.7 (0.6 to 1.0$)$ & 1.7 (1.1 to 2.6$)$ \\
\hline & Sultan et al ${ }^{21}$ & 5.2 & $0.60(0.15$ to 0.95$)$ & $0.31(0.22$ to 0.42$)$ & 0.9 (0.4 to 1.8$)$ & 1.3 (0.4 to 3.8$)$ \\
\hline \multirow{3}{*}{$\begin{array}{l}\text { History of } \\
\text { previous } \\
\text { antibiotic use }\end{array}$} & Baldwin et $a l^{19}$ & 25.9 & $0.22(0.12$ to 0.37$)$ & 0.94 (0.88 to 0.97$)$ & 3.5 (1.5 to 7.9$)$ & 0.8 (0.7 to 1.0$)$ \\
\hline & Kocher et al ${ }^{14}$ & 33.1 & 0.12 (0.04 to 0.24$)$ & 0.83 (0.74 to 0.89$)$ & 0.7 (0.3 to 1.6$)$ & 1.1 (0.9 to 1.2$)$ \\
\hline & Luhmann et al ${ }^{15}$ & 28.5 & $0.32(0.19$ to 0.47$)$ & 0.82 (0.74 to 0.89$)$ & 1.8 (1.0 to 3.2$)$ & 0.8 (0.7 to 1.0$)$ \\
\hline Lyme season & Deanehan et $a l^{16}$ & 2.7 & $0.38(0.14$ to 0.68$)$ & 0.56 (0.51 to 0.61$)$ & 0.9 (0.4 to 1.8$)$ & 1.1 (0.7 to 1.7$)$ \\
\hline $\begin{array}{l}\text { Previous } \\
\text { healthcare visit }\end{array}$ & Luhmann et al ${ }^{15}$ & 28.5 & $0.64(0.49$ to 0.77$)$ & $0.55(0.46$ to 0.64$)$ & $1.4(1.1$ to 1.9$)$ & $0.7(0.4$ to 1.0$)$ \\
\hline \multirow{2}{*}{$\begin{array}{l}\text { History of recent } \\
\text { illness }\end{array}$} & Baldwin et $a l^{19}$ & 28.5 & 0.24 (0.13 to 0.39$)$ & 0.87 (0.80 to 0.92$)$ & 1.9 (1.0 to 3.7$)$ & $0.9(0.7$ to 1.0$)$ \\
\hline & Deanehan et al ${ }^{16}$ & 2.8 & $0.46(0.19$ to 0.75$)$ & $0.83(0.79$ to 0.86$)$ & 2.7 (1.5 to 5.1$)$ & 0.7 (0.4 to 1.1$)$ \\
\hline $\begin{array}{l}\text { History of tick } \\
\text { bite }\end{array}$ & Deanehan et $a l^{16}$ & 1.7 & $0.00(0.00$ to 0.52$)$ & 0.86 (0.82 to 0.90$)$ & NA & $1.2(1.1$ to 1.2$)$ \\
\hline
\end{tabular}

\section{Examination}

\begin{tabular}{|c|c|c|c|c|c|c|}
\hline \multirow{3}{*}{$\begin{array}{l}\text { Fever } \\
\text { documented, } \\
\text { but not defined }\end{array}$} & Baldwin et $a l^{19}$ & 25.9 & 0.80 (0.66 to 0.90$)$ & 0.59 (0.51 to 0.68$)$ & 2.0 (1.5 to 2.5$)$ & 0.3 (0.2 to 0.6$)$ \\
\hline & Deanehan et $a l^{16}$ & 2.8 & 0.77 (0.46 to 0.95$)$ & 0.73 (0.68 to 0.77 ) & 2.8 (2.0 to 3.9 ) & 0.3 (0.1 to 0.9$)$ \\
\hline & Heyworth et $a 1^{12}$ & 32.6 & 0.27 (0.08 to 0.55$)$ & 0.94 (0.79 to 0.99 ) & 4.1 (0.9 to 20.1$)$ & 0.8 (0.6 to 1.1$)$ \\
\hline $\begin{array}{l}\text { Temperature } \\
\geq 37.0^{\circ} \mathrm{C}\end{array}$ & Jung et $a l^{23}$ & 21.8 & 0.78 (0.58 to 0.91$)$ & 0.97 (0.91 to 0.99 ) & 25.2 (8.1 to 78.0$)$ & 0.2 (0.1 to 0.5$)$ \\
\hline \multirow{2}{*}{$\begin{array}{l}\text { Temperature } \\
\geq 37.5^{\circ} \mathrm{C}\end{array}$} & Del Beccaro et $a^{22}$ & 29.9 & 0.66 (0.49 to 0.80$)$ & 0.70 (0.59 to 0.79 ) & 2.2 (1.5 to 3.2 ) & 0.5 (0.3 to 0.8$)$ \\
\hline & Kuda et $a l^{24}$ & 27.3 & 1.00 (0.66 to 1.00$)$ & 0.67 (0.45 to 0.84$)$ & 3.0 (1.7 to 5.3$)$ & NA \\
\hline \multirow{3}{*}{$\begin{array}{l}\text { Temperature } \\
\geq 38.0^{\circ} \mathrm{C}\end{array}$} & Del Beccaro et $a l^{22}$ & 29.9 & 0.45 (0.29 to 0.62$)$ & 0.85 (0.76 to 0.92$)$ & 3.1 (1.7 to 5.7$)$ & 0.7 (0.5 to 0.9$)$ \\
\hline & Faesch et $a l^{11}$ & 14.2 & $0.60(0.45$ to 0.74$)$ & 0.85 (0.80 to 0.89$)$ & $4.0(2.8$ to 5.7$)$ & 0.5 (0.3 to 0.7$)$ \\
\hline & Sultan et $a l^{21}$ & 5.2 & 1.00 (0.48 to 1.00$)$ & 0.90 (0.82 to 0.95$)$ & 10.1 (5.4 to 18.8$)$ & NA \\
\hline \multirow{6}{*}{$\begin{array}{l}\text { Temperature } \\
\geq 38.5^{\circ} \mathrm{C}\end{array}$} & Caird et $a l^{18}$ & 70.8 & 0.44 (0.27 to 0.62$)$ & 1.00 (0.77 to 1.00$)$ & NA & 0.6 (0.4 to 0.8$)$ \\
\hline & Kocher et $\mathrm{al}^{13}$ & 48.8 & $0.82(0.72$ to 0.89$)$ & 0.92 (0.84 to 0.97$)$ & 10.0 (4.9 to 20.6 ) & $0.2(0.1$ to 0.3$)$ \\
\hline & Kocher et al ${ }^{14}$ & 33.1 & 0.61 (0.46 to 0.74$)$ & 0.76 (0.66 to 0.84$)$ & 2.5 (1.7 to 3.8 ) & $0.5(0.4$ to 0.7$)$ \\
\hline & Kuda et $a l^{24}$ & 27.3 & 0.78 (0.40 to 0.97$)$ & 0.92 (0.73 to 0.99 ) & 9.3 (2.4 to 36.8 ) & 0.2 (0.1 to 0.8$)$ \\
\hline & Luhmann et al ${ }^{15}$ & 28.5 & 0.72 (0.57 to 0.84$)$ & 0.65 (0.56 to 0.74$)$ & 2.1 (1.5 to 2.8 ) & $0.4(0.3$ to 0.7$)$ \\
\hline & Sultan et $a l^{21}$ & 5.2 & 0.80 (0.28 to 0.99$)$ & 0.96 (0.86 to 0.99 ( & 18.2 (6.4 to 52.2$)$ & $0.2(0.0$ to 1.2$)$ \\
\hline Joint tendernes & Baldwin et $a l^{19}$ & 25.9 & 0.73 (0.59 to 0.85$)$ & 0.94 (0.88 to 0.97 ) & 11.4 (5.9 to 22.0$)$ & $0.3(0.2$ to 0.5$)$ \\
\hline
\end{tabular}


Table 2 Continued

\begin{tabular}{|c|c|c|c|c|c|c|}
\hline \multirow[b]{2}{*}{ Risk factors } & \multirow[b]{2}{*}{ Study } & \multirow{2}{*}{$\begin{array}{l}\text { Prevalence } \\
\text { of SA, \% }\end{array}$} & \multirow{2}{*}{$\begin{array}{l}\text { Sensitivity } \\
(95 \% \mathrm{Cl})\end{array}$} & \multirow{2}{*}{$\begin{array}{l}\text { Specificity } \\
\text { (95\% Cl) }\end{array}$} & \multicolumn{2}{|c|}{ Likelihood ratio $(95 \% \mathrm{Cl})$} \\
\hline & & & & & Positive (LR+) & Negative (LR-) \\
\hline $\begin{array}{l}\text { Limited range of } \\
\text { motion }\end{array}$ & Deanehan et al ${ }^{16}$ & 2.8 & $0.92(0.64$ to 1.00$)$ & $0.30(0.26$ to 0.34$)$ & $1.3(1.1$ to 1.6$)$ & $0.3(0.0$ to 1.7$)$ \\
\hline \multirow[t]{2}{*}{ Joint warmth } & Baldwin et $a l^{19}$ & 25.9 & $0.82(0.68$ to 0.91$)$ & $0.56(0.48$ to 0.65$)$ & 1.9 (1.5 to 2.4$)$ & $0.3(0.2$ to 0.6$)$ \\
\hline & Deanehan et $a l^{16}$ & 3.1 & $0.83(0.52$ to 0.98$)$ & $0.40(0.35$ to 0.45$)$ & $1.4(1.1$ to 1.8$)$ & $0.4(0.1$ to 1.5$)$ \\
\hline \multirow{4}{*}{$\begin{array}{l}\text { Non-weight } \\
\text { bearing }\end{array}$} & Deanehan et $a l^{16}$ & 2.7 & $0.33(0.10$ to 0.65$)$ & $0.76(0.72$ to 0.80$)$ & 1.4 (0.6 to 3.2) & 0.9 (0.6 to 1.3) \\
\hline & Heyworth et al $l^{12}$ & 32.6 & $0.93(0.68$ to 1.00$)$ & $0.19(0.07$ to 0.37$)$ & 1.2 (0.9 to 1.4$)$ & $0.3(0.1$ to 2.6$)$ \\
\hline & Kocher et al ${ }^{13}$ & 48.8 & 0.95 (0.88 to 0.99$)$ & $0.65(0.54$ to 0.75$)$ & 2.7 (2.0 to 3.7$)$ & 0.1 (0.0 to 0.2$)$ \\
\hline & Kocher et $a l^{14}$ & 33.1 & $0.84(0.71$ to 0.93$)$ & $0.51(0.41$ to 0.61$)$ & 1.7 (1.4 to 2.2$)$ & $0.3(0.2$ to 0.6$)$ \\
\hline
\end{tabular}

elevated WBC count varied between studies, ranging from $\geq 11.0 \times 10^{9} / \mathrm{L}$ to $\geq 15.0 \times 10^{9} / \mathrm{L}$. Irrespective of the definition used, the presence or absence of an elevated WBC count did not significantly change the odds of septic arthritis.

The performance of an elevated ESR count was evaluated in seven studies. ${ }^{12} 18$ 20-24 The definition of an elevated ESR varied from ESR $>20 \mathrm{~mm} /$ hour to ESR $>75$ $\mathrm{mm} /$ hour. Positive LR for an elevated ESR ranged from 1.2 to 12 , with negative LR ranging from 0.1 to 0.9 .

The definition of an elevated CRP level also varied, ranging from CRP $\geq 7 \mathrm{mg} / \mathrm{L}$ to $\geq 105 \mathrm{mg} / \mathrm{L}$. ${ }^{12} 1820{ }^{23}$ Positive LR for an elevated CRP ranged from 1.2 to 12.3, with negative LR ranging from 0.1 to 0.7 .

A single prospective study of 339 children presenting with non-traumatic decreased range of motion of a skeletal segment found that a procalcitonin $\geq 0.5 \mathrm{ng} / \mathrm{mL}$ was highly specific $(0.97 ; 95 \%$ CI 0.94 to 0.99$)$ for the diagnosis of septic arthritis, but had a very low sensitivity $(0.13$; $95 \%$ CI 0.05 to 0.25$).{ }^{11}$

A synovial WBC count $\geq 100000$ cells $/ \mu \mathrm{L}$ has traditionally been used as one of the diagnostic criteria for septic arthritis. Conversely, a synovial WBC count $\leq 25000$ cells/ $\mu \mathrm{L}$ is generally seen to exclude septic arthritis. However, two studies examining a range of synovial WBC counts between 25000 and 100000 cells $/ \mu \mathrm{L}$ did not identify a cut-off with a clinically useful positive or negative LR. ${ }^{12} 17$

\section{Radiographic variables}

Six studies evaluated the role of plain radiographs for the diagnosis of septic arthritis in the child presenting with non-traumatic limp, but had inconsistent findings (table 5). ${ }^{13} 1419222328$

A single study of 30 children found that the presence of an ultrasonographic effusion moderately increased the risk of septic arthritis (LR+ 8.4; 95\% CI 4.1 to 17.1), while the absence of an ultrasonographic effusion moderately reduced the risk of septic arthritis (LR- 0.2; 95\% CI 0.1 to 0.3$).^{25}$

MRI was evaluated in two studies, which together examined 41 patients, 16 of whom had with septic arthritis. ${ }^{26} 27$ Various findings were assessed, with a range of diagnostic utility.

Separate summary receiver operator curves are presented for fever, features on history, features on examination, WBC count, CRP level, ESR level, synovial fluid findings, X-ray, ultrasound and MRI in online supplemental materials 3-11.

\section{Clinical risk prediction tools}

Our review identified two multivariate clinical risk prediction tools for septic arthritis among children presenting with non-traumatic limp that have had their validity assessed in populations separate to their derivation sample.

The four components of prediction tool by Kocher et $a l^{13}$ are non-weight-bearing status, fever, raised WBC count $\left(\geq 12 \times 10^{9} / \mathrm{L}\right)$ and raised ESR $(\geq 40 \mathrm{~mm} /$ hour $)$ (table 3). ${ }^{14} 151821$ Caird $e t a l^{18}$ derived an alternative prediction tool that included a fifth parameter, CRP $\geq 20$ $\mathrm{mg} / \mathrm{L}$, in addition to original four-predictor model by Kocher et al (table 3).

Notably, the performances of both clinical risk prediction tools are significantly worse in external validation studies (table 3). In original derivation study by Kocher et al, the predicted probability of a child presenting with non-traumatic limp having septic arthritis was $99.6 \%$ when all four components were present. However, when this clinical risk prediction tool was applied in two external validation studies, the predicted probability of septic arthritis ranged from $58.1 \%$ to $93 \%$. The area under the receiver-operator curve was also notably lower in both studies compared with original derivation study by Kocher et al $\left(0.80^{15}\right.$ and $0.86,{ }^{14}$ respectively compared with 0.96$)$. 
Table 3 Sensitivities, specificities and likelihood ratios for laboratory findings

\begin{tabular}{|c|c|c|c|c|c|c|}
\hline \multirow[b]{2}{*}{$\begin{array}{l}\text { Serum laboratory } \\
\text { values }\end{array}$} & \multirow[b]{2}{*}{ Study } & \multirow[b]{2}{*}{$\begin{array}{l}\text { Prevalence } \\
\text { of SA, } \%\end{array}$} & \multirow[b]{2}{*}{$\begin{array}{l}\text { Sensitivity } \\
(95 \% \mathrm{Cl})\end{array}$} & \multirow[b]{2}{*}{$\begin{array}{l}\text { Specificity } \\
(95 \% \mathrm{Cl})\end{array}$} & \multicolumn{2}{|c|}{ Likelihood ratio (95\% Cl) } \\
\hline & & & & & Positive (LR+) & $\begin{array}{l}\text { Negative } \\
\text { (LR-) }\end{array}$ \\
\hline \multicolumn{7}{|c|}{ White blood cell count (WBC) } \\
\hline $\begin{array}{l}\text { WBC bands } \\
\geq 350 / \mathrm{mm}^{3}\end{array}$ & Del Beccaro et al ${ }^{22}$ & 31.2 & 0.53 (0.35 to 0.70$)$ & 0.75 (0.64 to 0.84$)$ & 2.1 (1.3 to 3.4$)$ & $0.6(0.4$ to 0.9$)$ \\
\hline$\geq 11.0 \times 10^{9} / \mathrm{L}$ & Jung et $a l^{23}$ & 21.8 & 0.74 (0.54 to 0.89$)$ & 0.94 (0.87 to 0.98$)$ & $12.0(5.4$ to 26.8$)$ & $0.3(0.2$ to 0.5$)$ \\
\hline \multirow[t]{3}{*}{$\geq 12.0 \times 10^{9} / \mathrm{L}$} & Caird et $a l^{18}$ & 70.8 & 0.50 (0.32 to 0.68$)$ & 0.71 (0.42 to 0.92$)$ & $1.8(0.7$ to 4.3$)$ & $0.7(0.4$ to 1.1$)$ \\
\hline & Heyworth et a $\left.\right|^{12}$ & 32.6 & $0.47(0.21$ to 0.73$)$ & $0.55(0.36$ to 0.73$)$ & $1.0(0.5$ to 2.0$)$ & $1.0(0.6$ to 1.7$)$ \\
\hline & Sultan et $\left.a\right|^{21}$ & 5.2 & $0.40(0.05$ to 0.85$)$ & $0.81(0.72$ to 0.89$)$ & $2.1(0.7$ to 6.8$)$ & 0.7 (0.4 to 1.5$)$ \\
\hline \multirow[t]{2}{*}{$\geq 15.0 \times 10^{9} / \mathrm{L}$} & Del Beccaro et $a l^{22}$ & 29.2 & $0.26(0.13$ to 0.43$)$ & $0.84(0.75$ to 0.91$)$ & $1.6(0.8$ to 3.3$)$ & $0.9(0.7$ to 1.1$)$ \\
\hline & Kuda et $a l^{24}$ & 27.3 & 0.78 (0.40 to 0.97$)$ & 0.75 (0.53 to 0.90$)$ & 3.1 (1.4 to 6.8$)$ & $0.3(0.1$ to 1.0$)$ \\
\hline \multicolumn{7}{|c|}{ Erythrocyte sedimentation rate (ESR) } \\
\hline \multirow[t]{3}{*}{$\geq 20 \mathrm{~mm} /$ hour } & Del Beccaro et $a l^{22}$ & 29.2 & 0.79 (0.63 to 0.90$)$ & $0.72(0.61$ to 0.81$)$ & 2.8 (1.9 to 4.0$)$ & $0.3(0.2$ to 0.6$)$ \\
\hline & Jung et $\left.a\right|^{23}$ & 21.8 & 0.93 (0.76 to 0.99$)$ & 0.59 (0.48 to 0.69$)$ & $2.3(1.7$ to 2.9$)$ & 0.1 (0.0 to 0.5$)$ \\
\hline & Kuda et $\left.a\right|^{24}$ & 27.3 & $1.00(0.66$ to 1.00$)$ & 0.75 (0.53 to 0.90$)$ & $4.0(2.0$ to 8.0$)$ & NA \\
\hline$\geq 25 \mathrm{~mm} /$ hour & Levine et $a l^{20}$ & 31.5 & 0.92 (0.79 to 0.98$)$ & $0.22(0.14$ to 0.33$)$ & $1.2(1.0$ to 1.4$)$ & 0.3 (0.1 to 1.1$)$ \\
\hline$\geq 30 \mathrm{~mm} /$ hour & Del Beccaro et $a l^{22}$ & 29.2 & 0.71 (0.54 to 0.85$)$ & 0.86 (0.77 to 0.92$)$ & 5.0 (2.9 to 8.7$)$ & $0.3(0.2$ to 0.6$)$ \\
\hline \multirow[t]{4}{*}{$\geq 40 \mathrm{~mm} /$ hour } & Caird et $a l^{18}$ & 70.8 & 0.56 (0.38 to 0.73$)$ & 0.86 (0.57 to 0.98$)$ & 3.9 (1.1 to 14.6$)$ & 0.5 (0.3 to 0.8$)$ \\
\hline & Heyworth et $a l^{12}$ & 32.6 & $0.53(0.27$ to 0.79$)$ & $0.58(0.39$ to 0.75$)$ & $1.3(0.7$ to 2.4$)$ & $0.8(0.4$ to 1.5$)$ \\
\hline & Jung et $a l^{23}$ & 21.8 & 0.74 (0.54 to 0.89$)$ & 0.94 (0.87 to 0.98$)$ & $12.0(5.4$ to 26.8$)$ & $0.3(0.2$ to 0.5$)$ \\
\hline & Sultan et $a l^{21}$ & 5.2 & $0.40(0.05$ to 0.85$)$ & $0.88(0.79$ to 0.84$)$ & $3.3(1.0$ to 11.1$)$ & 0.7 (0.3 to 1.4$)$ \\
\hline$\geq 50 \mathrm{~mm} /$ hour & Kuda et $\left.a\right|^{24}$ & 27.3 & 0.67 (0.30 to 0.93$)$ & 0.92 (0.73 to 0.99$)$ & 8.0 (2.0 to 32.6$)$ & $0.4(0.1$ to 0.9$)$ \\
\hline$\geq 75 \mathrm{~mm} /$ hour & Levine et $a^{20}$ & 31.5 & 0.26 (0.13 to 0.42$)$ & 0.87 (0.78 to 0.93$)$ & $2.0(0.9$ to 4.3$)$ & $0.9(0.7$ to 1.1$)$ \\
\hline \multicolumn{7}{|c|}{$\mathrm{C}$ reactive protein (CRP) } \\
\hline$\geq 7 \mathrm{mg} / \mathrm{L}$ & Heyworth et $a l^{12}$ & 31 & $1.00(0.75$ to 1.00$)$ & 0.14 (0.04 to 0.32$)$ & $1.2(1.0$ to 1.3$)$ & NA \\
\hline \multirow[t]{2}{*}{$\geq 10 \mathrm{mg} / \mathrm{L}$} & Jung et $a l^{23}$ & 21.8 & 0.89 (0.71 to 0.98$)$ & 0.93 (0.86 to 0.97$)$ & $12.3(6.0$ to 25.5$)$ & 0.1 (0.0 to 0.4$)$ \\
\hline & Levine et $a l^{20}$ & 29.3 & $0.90(0.76$ to 0.97$)$ & $0.29(0.20$ to 0.39$)$ & $1.3(1.1$ to 1.5$)$ & $0.4(0.1$ to 1.0$)$ \\
\hline \multirow[t]{2}{*}{$\geq 20 \mathrm{mg} / \mathrm{L}$} & Caird et $a l^{18}$ & 70.8 & 0.85 (0.69 to 0.95$)$ & 0.71 (0.42 to 0.92$)$ & $3.0(1.3$ to 6.9$)$ & $0.2(0.1$ to 0.5$)$ \\
\hline & Sultan et $a l^{21}$ & 5.2 & $0.60(0.15$ to 0.95$)$ & 0.90 (0.82 to 0.95$)$ & $6.1(2.4$ to 15.6$)$ & $0.4(0.2$ to 1.3$)$ \\
\hline$\geq 50 \mathrm{mg} / \mathrm{L}$ & Levine et $a l^{20}$ & 29.3 & 0.67 (0.50 to 0.81$)$ & 0.67 (0.57 to 0.76$)$ & 2.0 (1.4 to 2.9$)$ & 0.5 (0.3 to 0.8$)$ \\
\hline$\geq 105 \mathrm{mg} / \mathrm{L}$ & Levine et $a l^{20}$ & 29.3 & 0.41 (0.26 to 0.58$)$ & 0.85 (0.76 to 0.92$)$ & $2.8(1.5$ to 5.1$)$ & 0.7 (0.5 to 0.9$)$ \\
\hline \multicolumn{7}{|l|}{ Serum procalcitonin } \\
\hline$\geq 0.5 \mathrm{ng} / \mathrm{mL}$ & Faesch et al ${ }^{11}$ & 14.2 & 0.13 (0.05 to 0.25$)$ & 0.97 (0.94 to 0.99$)$ & 4.0 (1.5 to 10.8$)$ & $0.9(0.8$ to 1.0$)$ \\
\hline \multicolumn{7}{|c|}{ Synovial fluid WBC count } \\
\hline$\geq 40000$ cells $/ \mu \mathrm{L}$ & Deanehan et $a l^{17}$ & 4.6 & 0.65 (0.38 to 0.86$)$ & 0.46 (0.40 to 0.51$)$ & $1.2(0.8$ to 1.7$)$ & 0.8 (0.4 to 1.5$)$ \\
\hline 50000 cells $/ \mu \mathrm{L}$ & Deanehan et $a l^{17}$ & 4.6 & 0.41 (0.18 to 0.67$)$ & 0.59 (0.54 to 0.64$)$ & $1.0(0.6$ to 1.8$)$ & $1.0(0.7$ to 1.5$)$ \\
\hline 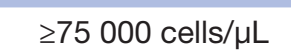 & Deanehan et $a l^{17}$ & 4.6 & $0.29(0.10$ to 0.56$)$ & 0.79 (0.74 to 0.83$)$ & $1.4(0.6$ to 3.0$)$ & $0.9(0.7$ to 1.2$)$ \\
\hline$\geq 100000$ cells $/ \mu \mathrm{L}$ & Deanehan et $a l^{17}$ & 4.6 & 0.24 (0.07 to 0.50$)$ & 0.89 (0.85 to 0.92$)$ & $2.2(0.9$ to 5.3$)$ & $0.9(0.7$ to 1.1$)$ \\
\hline $\begin{array}{l}25000-50000 \\
\text { cells } / \mathrm{mm}^{3}\end{array}$ & Heyworth et $a 1^{12}$ & 32.6 & 0.27 (0.08 to 0.55$)$ & $0.39(0.22$ to 0.58$)$ & $0.4(0.2$ to 1.1$)$ & 1.9 (1.1 to 3.2$)$ \\
\hline $\begin{array}{l}50000-75000 \\
\text { cells } / \mathrm{mm}^{3}\end{array}$ & Heyworth et $a l^{12}$ & 32.6 & 0.73 (0.45 to 0.92$)$ & 0.61 (0.42 to 0.78$)$ & 1.9 (1.1 to 3.2$)$ & $0.4(0.2$ to 1.1$)$ \\
\hline
\end{tabular}

NA, not available.

A similar observation was seen when the external validity of prediction tool by Caird et al was assessed in follow-up study by Sultan $e t a l,{ }^{21}$ with a comparable reduction noted in the predicted probability of a child having septic arthritis when all five predictors were present in a new population group $\left(60 \%{ }^{21}\right.$ compared with $\left.98 \%{ }^{18}\right)$. 
Table 4 Sensitivities, specificities and likelihood ratios for imaging findings

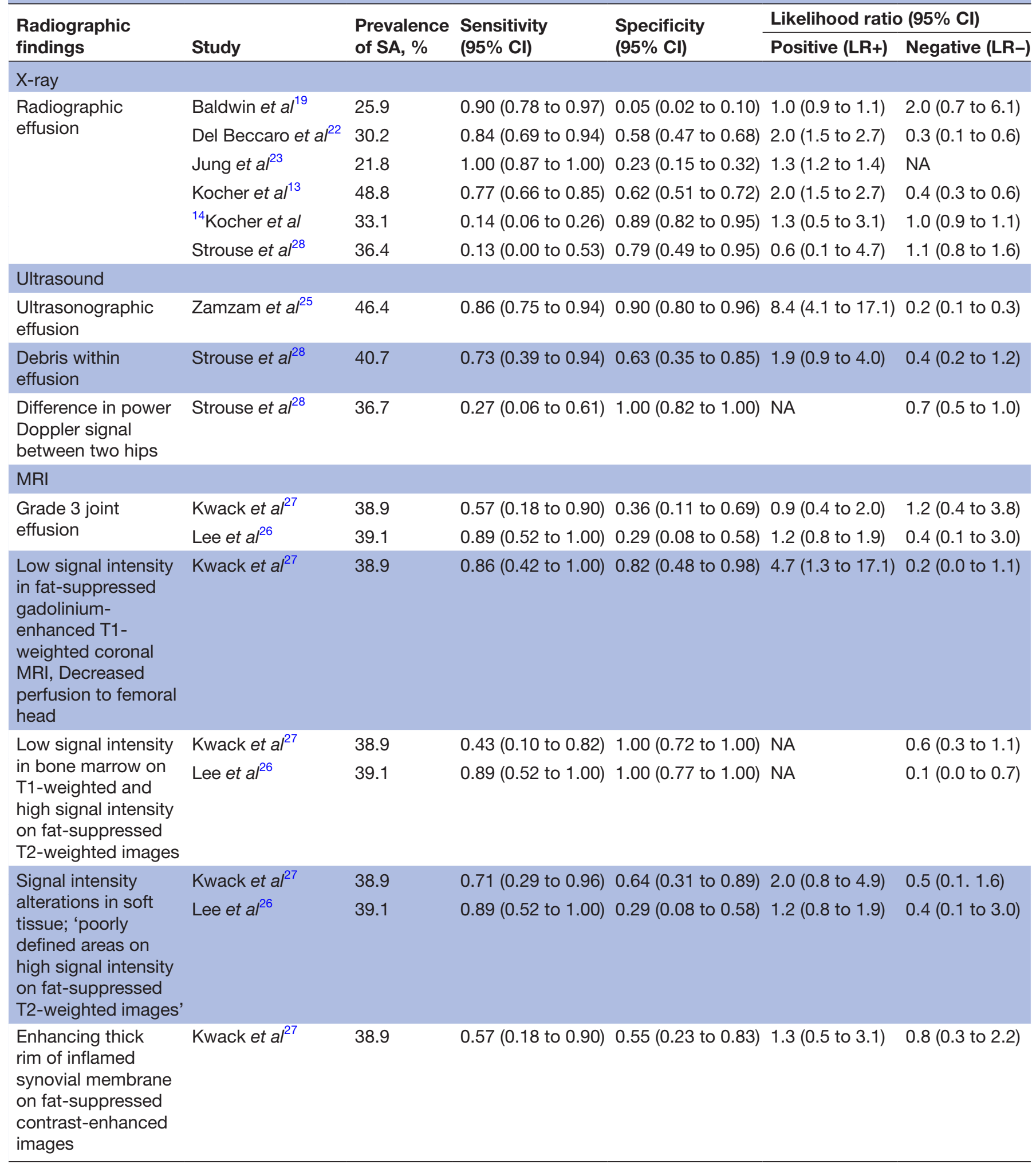

NA, not available.

\section{DISCUSSION}

The overall quality of the current literature used to inform the evaluation of a child presenting with acute non-traumatic limp to the ED is relatively low. It is difficult to apply the literature to children presenting to the ED with limp, due to spectrum bias, inconsistent definitions between studies, unclear temporal relationship between diagnostic tests and gold-standard diagnosis and poor performance of clinical risk prediction tools in external validation studies. 
Table 5 Sensitivities, specificities and likelihood ratios for clinical risk prediction tools

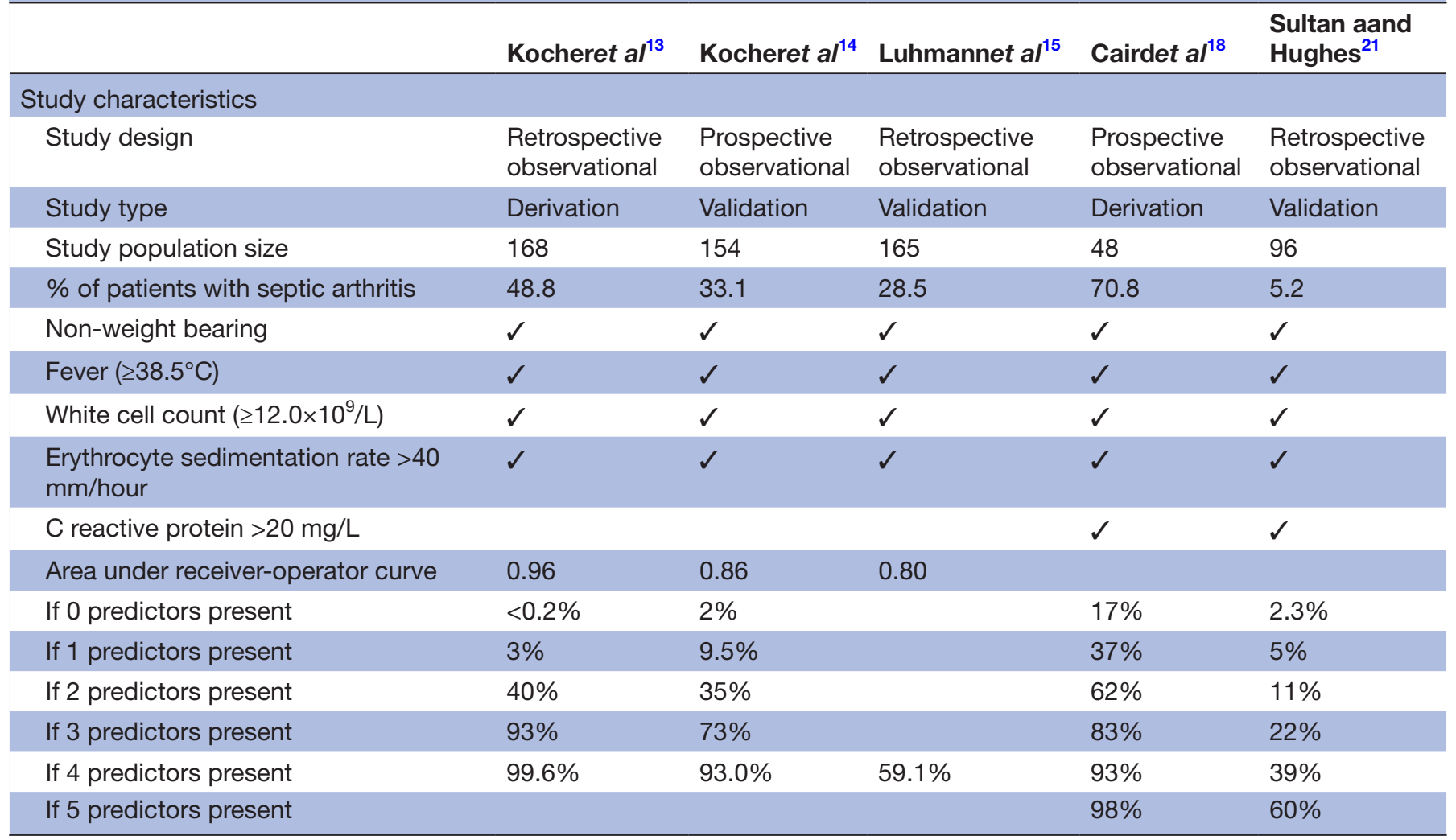

Spectrum bias occurs when differences exist in the prevalence of septic arthritis between the study and clinical setting. The prevalence of septic arthritis among children with non-traumatic limp varied from $5.2 \%{ }^{21}$ to $75.6 \%{ }^{18}$ in hospital inpatient or joint aspiration studies, while it was only $3 \%$ in an ED-based study population in a Lyme disease-endemic area. ${ }^{16}$ In high prevalence settings, the diagnostic performance of the evaluated clinical, biochemical and radiographic variables are likely to be an overestimate of their actual performance when applied to a more general ED population group.

It was difficult to determine the timing between assessment for specific variables and the time that diagnostic joint aspiration was performed to exclude or confirm a diagnosis of septic arthritis among children presenting with non-traumatic limp. For example, when considering the parameter 'fever', the timing of the fever was unclear (ie, pre-arrival, initial ED assessment or during their hospital inpatient stay). Furthermore, the timing between onset of symptoms and diagnostic testing was also indeterminable. This factor can have important ramifications for the diagnostic values of tests, such as CRP; for example, a low CRP after 3 days of symptoms may be expected to carry a higher sensitivity for septic arthritis than a low CRP 3 hours after symptom onset. ${ }^{29}$

A number of important variables did not have consistent definitions between studies. Different thresholds were used to define an 'abnormal' finding for fever, WBC count, CRP and ESR. This consequently leads to fragmentation of the aggregated data and smaller number of studies examining each definition.

Although appealing, the use of clinical risk prediction tools remains contentious. Key limitations of clinical risk prediction tools include poor performance in external validation studies, and the application of the tool originally to highly selected populations. This may be due to small sample sizes, a limited number of septic arthritis cases and differences in the prevalence of septic arthritis in derivation and validation samples. ${ }^{30}$ With relatively poor performance in external validation studies, it is difficult to justify the application of these tools to the ED setting.

No studies have assessed the application of clinical risk prediction tools to children presenting with acute nontraumatic limp to the ED. Kocher et al, ${ }^{13}$ Luhmann et al ${ }^{15}$ and Caird et $a l^{18}$ specifically examined children who underwent joint aspiration, while Sultan $e t a l^{21}$ examined children who were admitted as an inpatient for an unclear cause of limp. As the prevalence of septic arthritis was relatively higher in study populations by Kocher et $a l^{14}$ and Caird et $a l l^{18}$ the performance of both is likely to be lower when applied to the lower-risk ED population. Additionally, previously published prediction tools have excluded children who had 'later development of rheumatological disease', 'later development of Legg-Calvé-Perthes disease' and 'associated proximal femoral osteomyelitis'. This further undermines their applicability to the ED setting, where this information would not be available at the time of assessment. 


\section{Recommendations for future research}

Based on our review of the literature, considerable uncertainty remains regarding the optimal approach to evaluating for septic arthritis among children presenting with acute non-traumatic limp to the ED. Future studies should carefully address issues such as explicit definitions for index tests (ie, predictor variables), reporting the interval between the index test and reference standard, blinding outcome assessors to pertinent clinical and biochemical data and reporting follow-up after initial workup for those not undergoing a definitive diagnostic procedure. ${ }^{31}$ Incorporation of relevant elements of the QUADAS-2 tool and Standards for Reporting of Diagnostic Accuracy Study guidelines would likely lead to considerable improvement in future studies. ${ }^{8}$

Spectrum bias, variable performance and very select study populations have hampered the widespread uptake of existing clinical risk prediction tools. In order to accurately evaluate the diagnostic performance of clinical or investigation findings and clinical risk prediction tools in the ED setting, it is critical to conduct prospective observational studies. By recruiting children presenting with acute non-traumatic limp before a diagnosis of septic arthritis is established, research investigators would be able to prospectively collect clinical and basic investigation data at the time of initial ED assessment.

While the reference standard for children with septic arthritis has traditionally been a diagnostic joint aspiration with synovial fluid analysis, we acknowledge that such data would not be readily available on all patients who present with an acute non-traumatic limp to the ED. In clinical practice, very few children undergo a diagnostic joint aspiration and most children are managed conservatively.

The natural course of septic arthritis is such that longterm morbidity is likely to occur within days to weeks without prompt joint washout and antibiotic therapy, while non-emergent disorders are likely to self-resolve with time. ${ }^{5}$ As such, we suggest considering the use of a follow-up assessment to determine the presence of persistent symptoms, the need for further diagnostic testing and/or invasive procedures for prospective ED-based studies seeking to evaluate for septic arthritis among children presenting with acute non-traumatic limp.

\section{Limitations}

We searched only two electronic sources and limited our analysis to English-language articles from 1966 to June 2019. As such, we may have missed older manuscripts or non-English research reports. However, a rceent analysis suggests that the use of additional databases for most systematic reviews may be low yield.$^{32}$ Furthermore, with changes to epidemiology (increasing prevalence of methicillin-resistant Staphylococcus aureus) and vaccine coverage (Streptococcus pneumoniae and Haemophilus influenzae) over recent years, it is unclear how applicable older studies are to current clinical practice. Our review identified that the overall quality of the literature relevant to paediatric septic arthritis in the ED setting was poor to moderate, resulting in summary estimates that may be biased by several confounders.

Due to the limited number of ED-based studies in this area, children from other populations (ie, children who were admitted as an inpatient for exclusion of septic arthritis or who underwent a joint aspiration) were also included in this review. Pooled estimates of the data could not be performed because of the clinical heterogeneity between studies (ie, different settings, prevalence rates of septic arthritis and exclusion criteria). ${ }^{33}$

As previously discussed, our study objective sought to evaluate for septic arthritis among children presenting with lower limb complaints. Safe differentiation of children with septic arthritis from those with non-emergent disorders, such as transient synovitis, remains a diagnostic challenge for emergency physicians. We acknowledge that septic arthritis can present in other ways, such as the febrile or 'generally unwell' child, however, such studies that evaluated these presenting complaints were beyond the focus of our study objective and consequently not included in our analysis. Thus, the diagnostic utility of historical, biochemical and radiographic parameters for septic arthritis reported in our study cannot be extrapolated to children with non-lower limb presenting complaints.

\section{CONCLUSION}

No consensus currently exists on the optimal approach to evaluating for septic arthritis among children with acute non-traumatic limp, and commonly used clinical prediction tools appear unreliable. Clinical laboratory and imaging findings have, to date, been reported using varying definitions and cut-offs, and applied in differing study populations.

The presence or absence of joint tenderness, and an effusion on ultrasound appear to be useful, however, needs to be confirmed in future studies. Spectrum bias and overall poor-to-moderate quality study design limits applicability of currently available research to the acute ED setting. Existing clinical risk prediction tools are hampered by poor performance in external validation studies and very select study populations.

Differentiating children with septic arthritis from nonemergent disorders of non-traumatic limp remains a key diagnostic challenge for emergency physicians. There is a need for clinical risk prediction tools to be prospectively derived and validated in ED-based study populations.

\section{Author affiliations}

${ }^{1}$ Monash Health, Melbourne, Victoria, Australia

${ }^{2}$ School of Clinical Sciences at Monash Health, Monash University, Melbourne, Victoria, Australia

${ }^{3}$ Department of Paediatrics and Department of Paediatric Rheumatology, Monash Children's Hospital, Melbourne, Victoria, Australia

${ }^{4}$ Department of Paediatrics, School of Clinical Sciences, Monash University, Melbourne, Victoria, Australia 
${ }^{5}$ Austin Health, Melbourne, Victoria, Australia

${ }^{6}$ Pediatric Emergency Department, Monash Medical Centre, Emergency Service, Monash Health, Melbourne, Victoria, Australia

${ }^{7}$ Emergency Research, Murdoch Children's Research Institute, Parkville, Victoria, Australia

Correction notice This article has been corrected since it first published. The provenance and peer review statement has been included.

Twitter Simon Craig @DrSimonCraig

Contributors JT designed the data collection instructions, collected data, carried out the initial analyses, drafted the initial manuscript and reviewed and revised the manuscript. JC collected data, carried out the initial analyses and reviewed and revised the manuscript. PG conceptualised and designed the study and critically reviewed the manuscript for important intellectual content. SC conceptualised and designed the study, coordinated and supervised data collection and critically reviewed the manuscript for important intellectual content. All authors approved the final manuscript as submitted and agreed to be accountable for all aspects of the work

Funding The authors have not declared a specific grant for this research from any funding agency in the public, commercial or not-for-profit sectors.

Competing interests None declared.

Patient consent for publication Not required.

Ethics approval No ethics approval was required, as this was a systematic review of the published literature.

Provenance and peer review Not commissioned; externally peer reviewed.

Data availability statement № data are available. Apart from the information included in this publication and its supplementary material, no additional data are available.

Supplemental material This content has been supplied by the author(s). It has not been vetted by BMJ Publishing Group Limited (BMJ) and may not have been peer-reviewed. Any opinions or recommendations discussed are solely those of the author(s) and are not endorsed by BMJ. BMJ disclaims all liability and responsibility arising from any reliance placed on the content. Where the content includes any translated material, BMJ does not warrant the accuracy and reliability of the translations (including but not limited to local regulations, clinical guidelines, terminology, drug names and drug dosages), and is not responsible for any error and/or omissions arising from translation and adaptation or otherwise.

Open access This is an open access article distributed in accordance with the Creative Commons Attribution Non Commercial (CC BY-NC 4.0) license, which permits others to distribute, remix, adapt, build upon this work non-commercially, and license their derivative works on different terms, provided the original work is properly cited, appropriate credit is given, any changes made indicated, and the use is non-commercial. See: http://creativecommons.org/licenses/by-nc/4.0/.

ORCID iD

Simon Craig http://orcid.org/0000-0003-2594-1643

\section{REFERENCES}

1 Fischer SU, Beattie TF. The limping child: epidemiology, assessment and outcome. J Bone Joint Surg Br 1999;81:1029-34.

2 Jain N, Sah M, Chakraverty J, et al. Radiological approach to a child with hip pain. Clin Radiol 2013;68:1167-78.

3 Herman MJ, Martinek M. The Limping child. Pediatr Rev 2015:36:184-97.

4 Altemeier WA. Pediatric orthopedic infections: missed diagnoses. Pediatr Ann 1999;28:718-20.

5 Tse SML, Laxer RM. Approach to acute limb pain in childhood. Pediatrics in Review 2006;27:170-80.

6 Beach R. Minimally invasive approach to management of irritable hip in children. The Lancet 2000;355:1202-3.

7 McCanny PJ, McCoy S, Grant T, et al. Implementation of an evidence based guideline reduces blood tests and length of stay for the limping child in a paediatric emergency department. Emergency Medicine Journal 2013;30:19-23.
8 Whiting PF, Rutjes AWS, Westwood ME, et al. QUADAS-2: a revised tool for the quality assessment of diagnostic accuracy studies. Ann Intern Med 2011;155:529-36.

9 Cohen J. Weighted kappa: nominal scale agreement provision for scaled disagreement or partial credit. Psychol Bull 1968;70:213-20.

10 Willis BH. Spectrum bias--why clinicians need to be cautious when applying diagnostic test studies. Fam Pract 2008;25:390-6.

11 Faesch S, Cojocaru B, Hennequin C, et al. Can procalcitonin measurement help the diagnosis of osteomyelitis and septic arthritis? A prospective trial. Ital J Pediatr 2009;35:33.

12 Heyworth BE, Shore BJ, Donohue KS, et al. Management of pediatric patients with synovial fluid white Blood-Cell counts of 25,000 to $75,000 \mathrm{Cells} / \mathrm{mm} 3$ after aspiration of the hip. J Bone Joint Surg Am 2015;97:389-95.

13 Kocher MS, Zurakowski D, Kasser JR. Differentiating between septic arthritis and transient synovitis of the hip in children: an evidence-based clinical prediction algorithm. J Bone Joint Surg Am 1999;81:1662-70.

14 Kocher MS, Mandiga R, Zurakowski D, et al. Validation of a clinical prediction rule for the differentiation between septic arthritis and transient synovitis of the hip in children. J Bone Joint Surg Am 2004;86:1629-35.

15 Luhmann SJ, Jones A, Schootman M, et al. Differentiation between septic arthritis and transient synovitis of the hip in children with clinical prediction algorithms. J Bone Joint Surg Am 2004;86:956-62.

16 Deanehan JK, Kimia AA, Tan Tanny SP, et al. Distinguishing Lyme from septic knee monoarthritis in Lyme disease-endemic areas. Pediatrics 2013;131:e695-701.

17 Deanehan JK, Nigrovic PA, Milewski MD, et al. Synovial fluid findings in children with knee monoarthritis in Lyme disease endemic areas. Pediatr Emerg Care 2014;30:16-19.

18 Caird MS, Flynn JM, Leung YLEO, et al. Factors distinguishing septic arthritis from transient synovitis of the hip in children. J Bone Joint Surg Am 2006;88:1251-7.

19 Baldwin KD, Brusalis CM, Nduaguba AM, et al. Predictive factors for differentiating between septic arthritis and Lyme disease of the knee in children. J Bone Joint Surg Am 2016;98:721-8.

20 Levine MJ, McGuire KJ, McGowan KL, et al. Assessment of the test characteristics of C-reactive protein for septic arthritis in children. $J$ Pediatr Orthop 2003;23:373-7.

21 Sultan J, Hughes PJ. Septic arthritis or transient synovitis of the hip in children: the value of clinical prediction algorithms. J Bone Joint Surg Br 2010;92:1289-93.

22 Del Beccaro MA, Champoux AN, Bockers T, et al. Septic arthritis versus transient synovitis of the hip: the value of screening laboratory tests. Ann Emerg Med 1992;21:1418-22.

23 Jung ST, Rowe SM, Moon ES, et al. Significance of laboratory and radiologic findings for differentiating between septic arthritis and transient synovitis of the hip. J Pediatr Orthop 2003;23:368-72.

24 Kuda E, Al Wahadneh $\mathrm{A}$. The rational use of a local scoring system to differentiate between septic arthritis \& transient synovitis in children. Qatar Med J 2000;2000:16.

25 Zamzam MM. The role of ultrasound in differentiating septic arthritis from transient synovitis of the hip in children. J Pediatr Orthop $B$ 2006;15:418-22.

26 Lee SK, Suh KJ, Kim YW, et al. Septic arthritis versus transient synovitis at MR imaging: preliminary assessment with signal intensity alterations in bone marrow. Radiology 1999;211:459-65.

27 Kwack K-S, Cho JH, Lee JH, et al. Septic arthritis versus transient synovitis of the hip: gadolinium-enhanced MRI finding of decreased perfusion at the femoral epiphysis. American Journal of Roentgenology 2007;189:437-45.

28 Strouse PJ, DiPietro MA, Adler RS. Pediatric hip effusions: evaluation with power Doppler sonography. Radiology 1998;206:731-5.

29 Putto A, Ruuskanen O, Meurman O, et al. C reactive protein in the evaluation of febrile illness. Arch Dis Child 1986;61:24-9.

30 Uzoigwe CE. Another look: is there a flaw to current hip septic arthritis diagnostic algorithms? Clin Orthop Relat Res 2014:472:1645-51.

31 Kaji AH, Schriger D, Green S. Looking through the retrospectoscope: reducing bias in emergency medicine chart review studies. Ann Emerg Med 2014;64:292-8.

32 Hartling L, Featherstone R, Nuspl M, et al. The contribution of databases to the results of systematic reviews: a cross-sectiona study. BMC Med Res Methodol 2016;16:127.

$33 \mathrm{Kim} \mathrm{KW}$, Lee J, Choi SH, et al. Systematic review and meta-analysis of studies evaluating diagnostic test accuracy: a practical review for clinical Researchers-Part I. General guidance and tips. Korean J Radiol 2015;16:1175-87. 